\title{
The role of the efflux transporter P-glycoprotein in brain penetration of prednisolone
}

\author{
A M Karssen, O C Meijer, I C J van der Sandt, A G De Boer, \\ E C M De Lange and E R De Kloet
}

Divisions of Medical Pharmacology and Pharmacology, Leiden/Amsterdam Center for Drug Research/Leiden University Medical Centre, PO Box 9502, Leiden, 2300 RA, The Netherlands

(Requests for offprints should be addressed to A M Karssen; Email: Karssen@LACDR.LeidenUniv.nl)

\begin{abstract}
In the present study, we have investigated the role of the multidrug resistance (mdr) P-glycoprotein (Pgp) at the blood-brain barrier in hampering the access of the synthetic glucocorticoid, prednisolone.

In vivo, a tracer dose of $\left[{ }^{3} \mathrm{H}\right]$ prednisolone poorly penetrated the brain of adrenalectomised wild-type mice, but the uptake was more than threefold enhanced in the absence of Pgp expression in mdr1a $(-/-)$ mice. In vitro, in stably transfected LLC-PK1 monolayers the human MDR1 P-glycoprotein was able to transport prednisolone present at a micromolar concentration. A specific Pgp blocker, LY 335979, could block this polar transport of
\end{abstract}

$\left[{ }^{3} \mathrm{H}\right]$ prednisolone. Human Pgp does not transport all steroids, as cortexolone was not transported at all and aldosterone was only weakly transported.

The ability of Pgp to export the synthetic glucocorticoid, prednisolone, suggests that uptake of prednisolone in the human brain is impaired, leading to a discrepancy between central and peripheral actions. Furthermore, the ensuing imbalance in activation of the two types of brain corticosteroid receptors may have consequences for cognitive performance and mood.

Journal of Endocrinology (2002) 175, 251-260

\section{Introduction}

The synthetic glucocorticoids prednisolone and dexamethasone are widely used as anti-inflammatory and immunosuppressive drugs, because of their potent glucocorticoid actions in combination with their low mineralocorticoid (salt-retaining) actions. These actions are mediated by glucocorticoid receptors (GR) and mineralocorticoid receptors (MR) respectively (De Kloet et al. 1998). Both types of corticosteroid receptors are present in the brain. Glucocorticoid treatment, therefore, has major effects on cognitive function (Belanoff et al. 2001b), whereas blockade of GR action seems to be a promising anti-depression strategy (Belanoff et al. 2001a). Glucocorticoids are commonly believed to cross endothelial barriers with relative ease because of their highly lipophilic nature and their small size. However, we recently demonstrated that the penetration of dexamethasone into mouse brain is hampered because the multidrug resistance 1a (mdr1a) P-glycoprotein (Pgp) excludes this high affinity GR ligand from the brain (Schinkel et al. 1995, Meijer et al. 1998). The drug-transporting Pgp is expressed at the luminal membranes of endothelial cells of the blood-brain barrier (BBB) (Cordon-Cardo et al. 1989, Thiebaut et al. 1989). This transmembrane protein is encoded by the mdr1a gene in rodents and by the highly homologous MDR1 gene in humans (Jette et al. 1995, Van de Vrie et al. 1998). We hypothesised that the synthetic GR ligand, prednisolone, is also a substrate of this efflux transporter and is thus hampered in its ability to enter the glucocorticoid target areas in the brain. A poor penetration of the BBB by this synthetic glucocorticoid may have important implications for its actions on brain function.

Pgp-mediated transport is not a common feature of steroids. We have examined Pgp-mediated transport of several naturally occurring corticosteroids. Recently, we have shown that there is a large difference in transport between the mixed MR/GR agonists cortisol and corticosterone (Karssen et al. 2001). Cortisol is transported by human MDR1 Pgp and, in line with the presence of MDR1 Pgp at the BBB, the levels of cortisol in human brain are decreased towards those of corticosterone. In contrast, the latter compound freely crosses the BBB in rodents as well as in man (Karssen et al. 2001). We now demonstrate the lack of robust Pgp-mediated transport for two other corticosteroids which are circulating in human plasma, i.e. the high affinity MR ligand, aldosterone and the precursor of cortisol, 11-deoxycortisol (cortexolone).

We have tested our main hypothesis about the role of $\mathrm{Pgp}$ at the $\mathrm{BBB}$ in reducing the penetration of 
prednisolone into the brain in two ways. First, we tested whether mdr1a Pgp at the mouse BBB limits in vivo brain penetration of prednisolone. For this purpose we have injected adrenalectomised mdr1a $(-/-)$ and wild-type mice with $\left[{ }^{3} \mathrm{H}\right]$ prednisolone with or without pretreatment with excess unlabelled prednisolone. Secondly, we have investigated in vitro whether the human homologue, MDR1 Pgp, is also able to transport prednisolone. Therefore, we measured polar transport in monolayers of pig kidney epithelial cells stably transfected with human cDNA of MDR1 Pgp compared with nontransfected host cells.

\section{Materials and Methods}

\section{In vivo distribution and autoradiography}

The in vivo distribution experiments were carried out as described previously (Meijer et al. 1998, Karssen et al. 2001) with some modifications. Male $\operatorname{mdr1} \mathrm{a}(-/-)$ and wild-type Friends virus B (FVB) mice were bred under specific pathogen free conditions at TNO (Leiden, The Netherlands). Male mice at the age of 18-23 weeks were used for this study. All experiments were carried out in accordance with the European Communities Council Directive 86/609/EEC and with approval from the animal care committee of the Faculty of Medicine, Leiden University (Leiden, The Netherlands).

After transport, the mice were housed individually at our laboratory, at ambient temperature and under a $12 \mathrm{~h} / 12 \mathrm{~h}$ lighting schedule (lights on at $0700 \mathrm{~h}$, lights off at $1900 \mathrm{~h}$ ) with free access to food and water.

To remove the source of endogenous corticosterone, mice were bilaterally adrenalectomised under gas anaesthesia (isoflurane) by a dorsal approach. After adrenalectomy (ADX), the animals had free access to $0.9 \%$ saline. At the time of the experiment the animals weighed $28 \pm 2 \cdot 0 \mathrm{~g}$ (mean \pm S.D.). Two days after ADX, the animals were subcutaneously injected with tritiated prednisolone (dissolved in $2 \%$ ethanol $/ 0.9 \%$ saline) for in vivo distribution. Wild-type $(n=9)$ and mutant mice $(n=6)$ were injected with $3 \cdot 5 \mu \mathrm{Ci} / 10 \mathrm{~g}\left[2,4,6,7-{ }^{3} \mathrm{H}\right]$ prednisolone (Amersham Pharmacia Biotech, UK, specific activity (SA) $48 \mathrm{Ci} / \mathrm{mmol})$. For in vivo autoradiography, mice $(n=2)$ were treated with $13.5 \mu \mathrm{Ci} / 10 \mathrm{~g}\left[{ }^{3} \mathrm{H}\right]$ prednisolone in a separate but similar experiment. As a control for nonspecific retention, one mouse of each genotype was pretreated with a 100-fold excess of unlabelled prednisolone (Sigma-Aldrich, Germany). One hour after injection the animals were decapitated. Trunk blood was collected in EDTA-coated tubes and centrifuged for determination of radioactivity and of remaining corticosterone in the plasma using a ${ }^{125} \mathrm{I}$-corticosterone radioimmunoassay kit (ICN Biomedicals, Inc., Costa Mesa, CA, USA). The brain was dissected and quickly frozen in isopentane precooled on dry ice/ethanol. Liver, testis, intestine and cerebellum were dissected and frozen on dry ice. All tissues were stored at $-80{ }^{\circ} \mathrm{C}$ until further use.

All organ tissues studied, except for the brain, were homogenised using Soluene-350 (Packard Bioscience, Groningen, The Netherlands). Hionic-Fluor (Packard Bioscience) was added to tissue homogenates, and plasma and radioactivity was determined in a Tricarb $\beta$-counter (Packard Instruments, Meriden, USA). Twelve-micrometre coronal sections of brain were cut on a cryostat and thaw-mounted on poly-L-lysine (Sigma Chemical Co., St Louis, MO, USA)-coated microscopic slides. The slides were put in an X-ray exposure holder (Amersham Pharmacia Biotech) and apposed to Ultrofilm (Leica Corp., Heerbrugg, Switzerland) for 18 months.

\section{Transepithelial transport and inhibition studies}

In order to examine the interactions of the glucocorticoid prednisolone, the mineralocorticoid aldosterone and the antiglucocorticoid cortexolone with the human $\mathrm{P}$-glycoprotein, we used monolayers of the porcine kidney epithelial cell-line LLC-PK1 and LLC-PK1 cells stably transfected with cDNA of the human MDR1 gene (LLC-PK1:MDR1). Cells obtained from the American Type Culture Collection (Manassas, VA, USA) were kindly provided by the Dutch Cancer Institute (Amsterdam, The Netherlands) (Schinkel et al. 1995). Human P-glycoprotein has been shown before to be specifically expressed on the apical surface of LLC:PK1:MDR1 cells in these monolayers (Ueda et al. 1992). Therefore, Pgp substrates entering these cells from the basal side will be translocated to the apical compartment, while those entering the apical membrane will be pumped back into the medium, thus resulting in polarised transport of substrates. This system models the way Pgp is likely to function in the BBB in excluding drugs from the brain (Yamazaki et al. 2001).

Cells were cultured at $37^{\circ} \mathrm{C}$ in the presence of $5 \%$ $\mathrm{CO}_{2}$ in complete medium, which consisted of DMEM (Biowhittaker Europe, Verviers, Belgium) supplied with $25 \mathrm{mM}$ HEPES and $4.5 \mathrm{~g} / 1$ glucose and supplemented with $100000 \mathrm{U} / 1$ penicillin, $100 \mathrm{mg} / \mathrm{l}$ streptomycin, $2 \mathrm{mM}$ L-glutamine and 10\% (vol/vol) foetal calf serum. The LLC-PK1 and LLC-PK1:MDR1 cell lines were subcultured by trypsinization every 3 to 4 days and medium was replaced twice a week.

During the experiments complete medium was used. The LLC-PK1 and LLC-PK1:MDR1 cells were seeded on microporous polycarbonate membrane filters $(0.4 \mu \mathrm{M}$ pore size, $12 \mathrm{~mm}$ diameter, Transwell, Costar, Corning BV, Schiphol-Rijk, The Netherlands) at a density of $120 \times 10^{3}$ cells $/ \mathrm{cm}^{2}$. The cells were grown for 5-6 days in complete medium with a medium replacement at day 3. Two hours before the start of the experiment, the medium was replaced with $800 \mu \mathrm{l}$ fresh medium at both the apical and basal side of the monolayer. In the inhibition 
experiments, one hour later the potent and selective P-glycoprotein blocker LY 335979 (1 $\mu$ M in water; kindly provided by Eli Lilly \& Co (USA)) or water was added at the basal side. To measure the transepithelial transport from the apical to the basal side or from the basal to the apical side $8 \mu \mathrm{l}$ of a 100 times stock of tritiated steroid in ethanol were added in triplicate at the apical or basal side respectively, at the start of the experiment $(\mathrm{t}=0)$. We have tested $\left[{ }^{3} \mathrm{H}\right]$ prednisolone, and $\left[1,2,6,7-{ }^{3} \mathrm{H}\right]$ aldosterone (Amersham Pharmacia Biotech, UK; SA $64 \mathrm{Ci} / \mathrm{mmol}$ ), $(1,2(\mathrm{n}))-\left[{ }^{3} \mathrm{H}\right]$ deoxycortisol (= cortexolone; NEN Life Science Products, Boston, USA; SA $57 \mathrm{Ci} / \mathrm{mmol}$ ) and, as a positive control, $\left[1,2,4,6,7-{ }^{3} \mathrm{H}\right]$ dexamethasone (Amersham Pharmacia Biotech, UK; SA $91 \mathrm{Ci} / \mathrm{mmol}$ ). As we were interested whether MDR1 Pgp was able to transport prednisolone even at high concentrations we supplemented $\left[{ }^{3} \mathrm{H}\right]$ prednisolone with $1 \mu \mathrm{M}$ unlabelled prednisolone. The starting concentrations for each experiment are mentioned in the legends of the corresponding Figures. Over the four hours of study, $75 \mu \mathrm{l}$ aliquots were taken once every hour from both compartments. Eight microlitre samples of the 100 times stock, and samples from the compartment opposite the one to which activity was added, were counted in a Tricarb $\beta$-counter after adding $3 \mathrm{ml}$ Emulsifier Safe (Packard). Basal-to-apical and apical-to-basal transport is presented as a percentage of total radioactivity added at the beginning of the experiment. Transepithelial electrical resistance was measured before and after the experiments to check the integrity of the monolayers (Gaillard \& De Boer 2000).

\section{Statistical analysis}

Mouse data were evaluated by Student's $t$-test. The results of the monolayer experiments were analysed by repeated measures ANOVA. Significance was taken at $P<0 \cdot 05$.

\section{Results}

Differences in brain uptake of $\left.{ }^{3} H\right]$ prednisolone in $m d r 1 a$ $(-/-)$ and wild-type mice

One hour after administration of $\left[{ }^{3} \mathrm{H}\right]$ prednisolone to ADX mice, the uptake of radioactivity in brain showed a clear difference between mdr1a $(-/-)$ mice and wildtype mice. After injection with $2 \cdot 5 \mu \mathrm{g} / \mathrm{kg}$ radiolabelled prednisolone the amount of radioactivity in cerebellum homogenates was $3 \cdot 2$-fold higher in mutants than in mdr1a $(+/+)$ mice (Table 1). The plasma levels of radioactivity were similar and the concentrations in the liver or any other peripheral tissue examined were not significantly different between the genotypes (Table 1). Comparable results were obtained after administration of $10 \mu \mathrm{g} / \mathrm{kg}\left[{ }^{3} \mathrm{H}\right]$ prednisolone (Table 1). Although absolute levels in all tissues and blood were obviously higher after
Table 1 Uptake of radioactivity in tissue homogenates and blood $1 \mathrm{~h}$ after administration of $\left[{ }^{3} \mathrm{H}\right]$ prednisolone at two dose levels. Results are means \pm S.E.M.

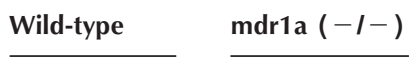

$\left[{ }^{3} \mathrm{H}\right]$ Prednisolone $(2 \cdot 5 \mu \mathrm{g} / \mathrm{kg})$

$n$

Cerebellum (nCi/mg)

Plasma $(\mathrm{nCi} / \mu \mathrm{l})$

Liver $(\mathrm{nCi} / \mathrm{mg})$

Testis $(\mathrm{nCi} / \mathrm{mg})$

Intestine $(\mathrm{nCi} / \mathrm{mg})$

$0.009 \pm 0.001 \quad 0 \cdot 030 \pm 0.001 *$

$0.044 \pm 0.003 \quad 0.043 \pm 0.001$

$1.443 \pm 0.076 \quad 1.565 \pm 0.147$

$0.030 \pm 0.001 \quad 0.033 \pm 0.003$

$1 \cdot 040 \pm 0 \cdot 246 \quad 1 \cdot 146 \pm 0 \cdot 325$

Brain/blood ratio

$0 \cdot 225 \pm 0 \cdot 022$

$0 \cdot 725 \pm 0 \cdot 026^{*}$

$\left[{ }^{3} \mathrm{H}\right]$ Prednisolone $(10 \mu \mathrm{g} / \mathrm{kg})$

$n$

Cerebellum ( $\mathrm{nCi} / \mathrm{mg})$

Plasma ( $\mathrm{nCi} / \mu \mathrm{l})$

Brain/blood ratio

2

$0 \cdot 050 \pm 0 \cdot 010$

$0 \cdot 247 \pm 0 \cdot 035$

2

$0 \cdot 225 \pm 0 \cdot 021^{*}$

$0 \cdot 337 \pm 0.034$

$0 \cdot 202 \pm 0 \cdot 014 \quad 0 \cdot 668 \pm 0 \cdot 004^{*}$

${ }^{*} P<0 \cdot 05$, Student's $t$-test, pretreated animals are not excluded from the analysis.

Table 2 Uptake of radioactivity in tissue homogenates and blood after pretreatment with unlabelled prednisolone

\section{Wild-type $\quad$ mdr1a $(-I-)$}

Pretreated with $0.25 \mathrm{mg} / \mathrm{kg}$ prednisolone followed by $2 \cdot 5 \mu \mathrm{g} / \mathrm{kg}\left[{ }^{3} \mathrm{H}\right]$ prednisolone

$\begin{array}{lll}n & 2 & 1 \\ \text { Cerebellum }(\mathrm{nCi} / \mathrm{mg}) & 0 \cdot 009 \pm 0 \cdot 001 & 0 \cdot 031 \\ \text { Plasma }(\mathrm{nCi} / \mu \mathrm{l}) & 0 \cdot 040 \pm 0 \cdot 003 & 0 \cdot 038 \\ \text { Liver }(\mathrm{nCi} / \mathrm{mg}) & 1 \cdot 244 \pm 0 \cdot 018 & 1 \cdot 234 \\ \text { Testis }(\mathrm{nCi} / \mathrm{mg}) & 0 \cdot 027 \pm 0 \cdot 002 & 0 \cdot 026 \\ \text { Intestine }(\mathrm{nCi} / \mathrm{mg}) & 1 \cdot 951 \pm 0 \cdot 533 & 2 \cdot 191 \\ \text { Brain/blood ratio } & 0 \cdot 222 \pm 0 \cdot 002 & 0 \cdot 645\end{array}$

Pretreated with $1 \mathrm{mg} / \mathrm{kg}$ prednisolone followed by $10 \mu \mathrm{g} / \mathrm{kg}\left[{ }^{3} \mathrm{H}\right]$ prednisolone

$\begin{array}{lll}n & 1 & 1 \\ \text { Cerebellum }(\mathrm{nCi} / \mathrm{mg}) & 0 \cdot 061 & 0 \cdot 204 \\ \text { Plasma }(\mathrm{nCi} / \mu \mathrm{l}) & 0 \cdot 282 & 0 \cdot 303 \\ \text { Brain/blood ratio } & 0 \cdot 216 & 0 \cdot 673\end{array}$

this higher dose, the brain-to-blood ratios were not significantly different from the ratios obtained after administration of the lower dose (Table 1). Remarkably, pretreatment with unlabelled prednisolone does not lead to any change in uptake of radioactivity in the cerebellum (Table 2). Thus, disruption of the mdr1a gene leads to enhanced uptake of prednisolone into the brain.

The autoradiograms also clearly demonstrate the difference between knockouts and controls. The mdr1a $(+/+)$ animals showed negligible labelling of brain tissue after administration of $\left[{ }^{3} \mathrm{H}\right]$ prednisolone (Fig. 1A). Labelling in brain sections was restricted to the cerebral ventricles. Some radioactive label seemed to have penetrated into the brain tissue around the ventricles, but the amount was considerably lower compared with the amount taken up 


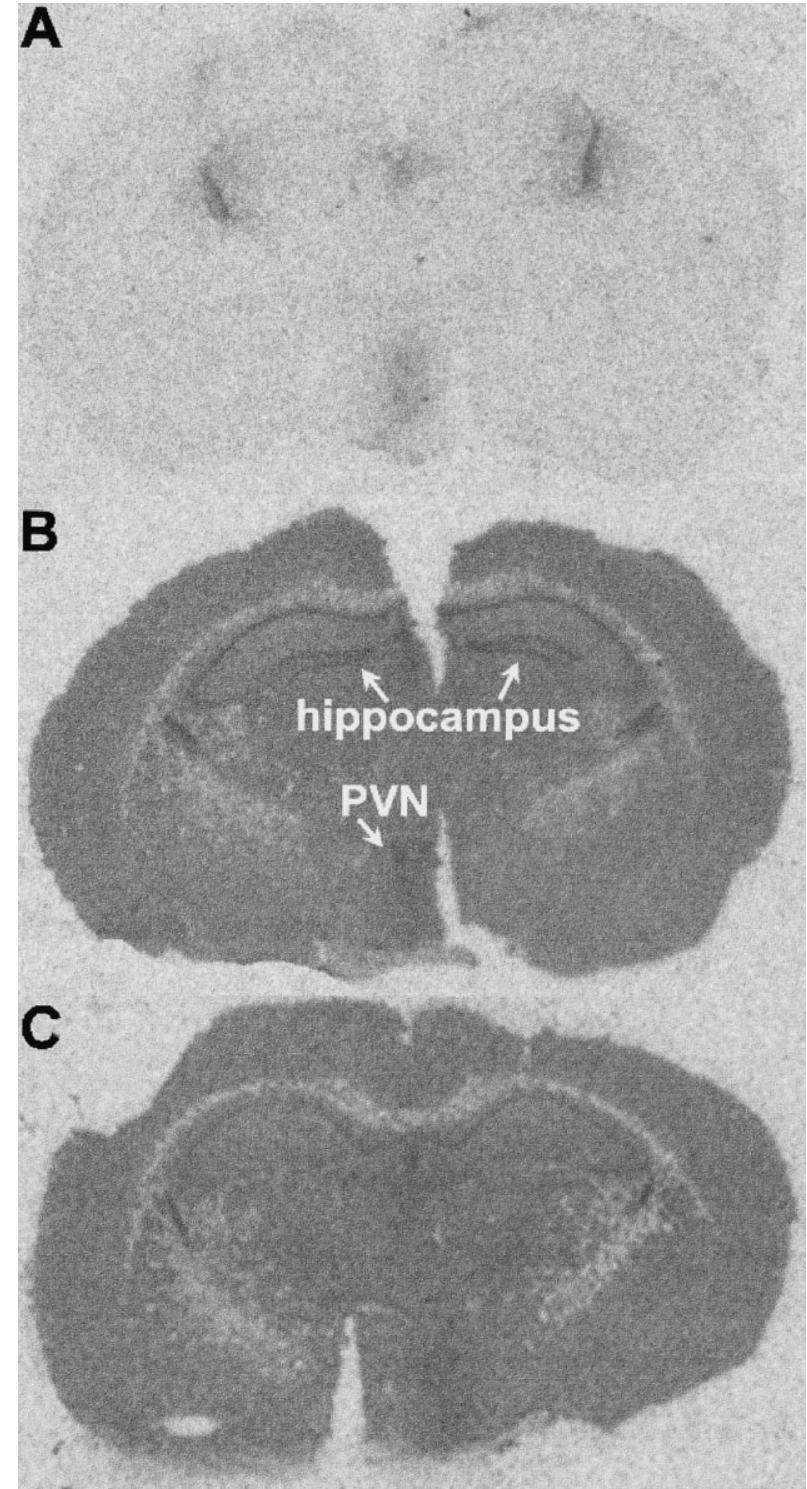

Figure 1 Representative autoradiograms of $12-\mu \mathrm{m}$ coronal sections of the brain demonstrate the large difference in uptake of $\left[{ }^{3} \mathrm{H}\right]$ prednisolone in wild-type (A) and mdr1a $(-/-)$ mouse (B) brains one hour after administration of $13.5 \mu \mathrm{Ci} / 10 \mathrm{~g}$ body weight. The dark spots in (A) represent transverse sectioning of the cerebroventricular space and adjacent ventricular walls.

Pretreatment with unlabelled prednisolone abolishes hippocampal labelling in mdr1a $(-/-)$ mouse brain but does not affect the labelling of the rest of the brain (C).

by the brain of mdr1a $(-/-)$ mice. These mutant mice showed increased labelling of whole brain (Fig. 1B). In particular, radioactivity was retained in the paraventricular nucleus (PVN) and hippocampal cell fields. These brain areas abundantly express GRs. Pretreatment with a 100fold excess of unlabelled prednisolone prevents this specific labelling (Fig. 1C). Remarkably, this pretreatment does not affect the labelling of the rest of the brain as was also shown in the cerebellum homogenates. Accordingly, these data clearly demonstrate that the presence of mdr1a Pgp in the $\mathrm{BBB}$ hampers the access of prednisolone to the mouse brain, particularly to the target areas within the brain that abundantly express GR.

\section{Transepithelial transport of prednisolone in monolayers of LLC-PK1 and LLC-PK1:MDR1 cells}

To test whether the human homologue of the mdr1a Pgp, MDR1 Pgp, is also able to transport prednisolone, we studied the transport capabilities of monolayers of pig kidney cells stably transfected with the human MDR1 cDNA compared with untransfected cells. Unlabelled prednisolone $(1 \mu \mathrm{M})$ supplemented with a tracer dose of $\left[{ }^{3} \mathrm{H}\right]$ prednisolone was added to the basal or apical compartment. Prednisolone was transported in a clear polarised fashion in the MDR1-transfected monolayers, but not in monolayers of the parental cells (Fig. 2A), indicating that the human Pgp is able to transport prednisolone, even at the high concentration tested. Polarised transport in MDR1 monolayers of prednisolone was abolished in the presence of LY 335979, a potent and selective Pgp blocker (Starling et al. 1997, Dantzig et al. 1999), resulting in similar fractions transported as in untransfected cells (Fig. 2B). This confirms that prednisolone transport is largely mediated by human P-glycoprotein.

As a positive control, we also assessed transepithelial transport of dexamethasone in our monolayers and demonstrated that MDR1 Pgp also efficiently transports this synthetic glucocorticoid (data not shown), as has been shown previously (Ueda et al. 1992, Schinkel et al. 1995).

Transepithelial transport of naturally occurring steroids in monolayers of LLC-PK1 and LLC-PK1:MDR1 cells

Furthermore, we tested corticosteroids that are naturally occurring in humans. Previously, we published the marked difference between transport of cortisol and corticosterone (Karssen et al. 2001). Now we focused on two additional corticosteroids, cortexolone and aldosterone. Cortexolone transport in the MDR1-transfected monolayers was not different from transport in monolayers of control cells (Fig. 3A), although polarised transport was observed in both cell lines which is probably caused by other renal transporters. This indicates the absence of human MDR1 Pgp-mediated transport of cortexolone. Administration of LY 335979 did not change the fraction of cortexolone translocated through the membrane (Fig. $3 \mathrm{~B})$, confirming the lack of Pgp contribution to the transport of cortexolone.

Examination of the transport of aldosterone shows that, although aldosterone displayed polarised transport in both transfected and parental monolayers, there was a small but 

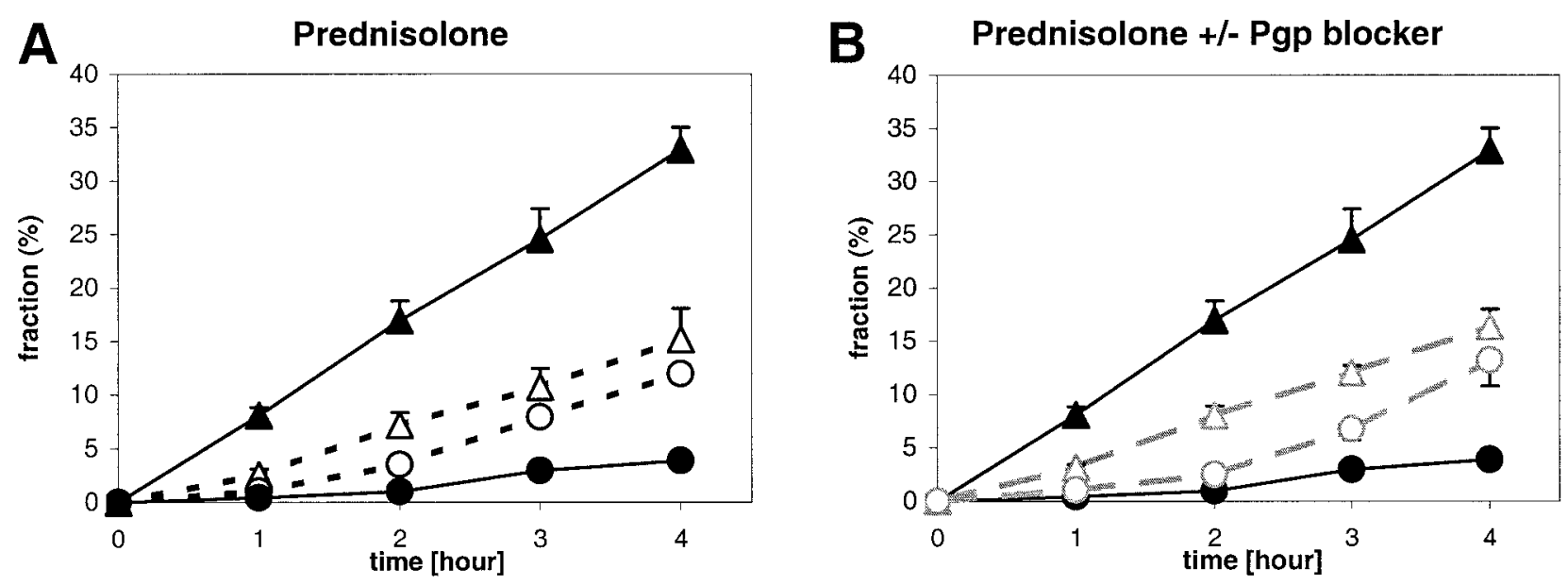

Figure 2 (A) Activity of $\left[{ }^{3} \mathrm{H}\right]$ prednisolone present in medium at different time points after adding $1 \mu \mathrm{M}$ prednisolone supplemented with $\left[{ }^{3} \mathrm{H}\right]$ prednisolone to the opposite compartment at $\mathrm{t}=0$. Transepithelial transport from the basal to apical $(\triangle, \mathbf{\Delta})$ and from the apical to basal $(\bigcirc, \mathbf{O})$ compartment was measured in wild-type LLC-PK1 (broken line) or MDR1-transfected LLC-PK1 (solid line) monolayers. (B) Transepithelial transport of prednisolone was measured in MDR1-transfected LLC-PK1 monolayers after adding $1 \mu$ M LY 335979 (broken line) or vehicle (water, solid line) $1 \mathrm{~h}$ before the start of the experiment. Results are presented as the fraction of the dose of radioactivity, which is $7 \mathrm{nM}$, added to the respective compartment. Each point represents the mean of three monolayers \pm S.E.M. Repeated measures ANOVA showed a significant interaction of time* ${ }^{*}$ cell type*transport for prednisolone in both $(A)$ and $(B)(P<0 \cdot 0001)$.

significant MDR1 Pgp contribution (Fig. 3C). This Pgpmediated transport could be partly blocked by LY 335979 (Fig. 3D). These results demonstrate that aldosterone is only weakly transported by MDR1 Pgp.

\section{Discussion}

The present study indicates that the efflux transporter Pgp at the level of the BBB decreases the degree of brain exposure to the synthetic glucocorticoid prednisolone. Our in vivo autoradiography data show that the mdr1a Pgp present in $\mathrm{BBB}$ hampers the penetration of $\left[{ }^{3} \mathrm{H}\right]$ prednisolone into the mouse brain, whereas our results with monolayers of human MDR1 cDNA-transfected LLCPK1 cells suggest that Pgp exports prednisolone from the human brain as well. We further demonstrated that aldosterone is transported by Pgp to a much smaller extent, while cortexolone is not transported at all.

Cells expressing P-glycoproteins are able to exclude a wide variety of structurally and functionally unrelated drugs, a phenomenon called multidrug resistance (Van de Vrie et al. 1998). It is now well established that Pgp is expressed in many normal tissues including the intestinal epithelium, the adrenals and brain capillary endothelial cells (Schinkel 1999). Several steroids such as dexamethasone and cortisol but not corticosterone are among its substrates (Ueda et al. 1992, Bourgeois et al. 1993, Ueda et al. 1996, Karssen et al. 2001). In the last decade, several studies have established the Pgp-mediated transport of the widely used synthetic glucocorticoid, dexamethasone. Pgp overexpressing cells accumulate reduced amounts of dexamethasone (Barnes et al. 1996), while the steroid is transported in a polarised fashion in monolayers of LLCPK1 cells transfected with MDR1 (Ueda et al. 1992, Schinkel et al. 1995, this study). Furthermore, dexamethasone penetration into mdr1a $(-/-)$ mouse brain is enhanced compared with wild-type brain (Schinkel et al. 1995), increasing the access to the glucocorticoid receptor (Meijer et al. 1998). While dexamethasone transport by Pgp has thus been convincingly demonstrated, information about Pgp-mediated transport of prednisolone is sparse. Bourgeois et al. (1993) have shown that murine thymoma cells expressing mdr1b Pgp are resistant to prednisolone (and dexamethasone)- induced apoptosis, but this second murine multidrug resistance Pgp is not expressed at the BBB. Our study clearly shows that both mouse mdr1a and human MDR1 Pgp transport prednisolone, as has been shown previously for dexamethasone and cortisol. This implies that any GR expressing cell type which also expresses the efflux transporter Pgp is resistant to these glucocorticoids, which is in line with the recent results of Pariante et al. (2001).

In contrast to these glucocorticoids, Pgp does not transport corticosterone (Karssen et al. 2001), a glucocorticoid that also circulates in human plasma but at 10-fold lower levels than cortisol and some other naturally occurring steroids. In line with the presence of MDR1 Pgp at the $\mathrm{BBB}$, the levels of cortisol in human brain are decreased towards the brain levels of corticosterone as measured in post mortem specimens with liquid chromatography-mass spectrometry (Karssen et al. 2001). We now demonstrate that Pgp is also unable to transport cortexolone, which is a weak partial agonist/antagonist at 

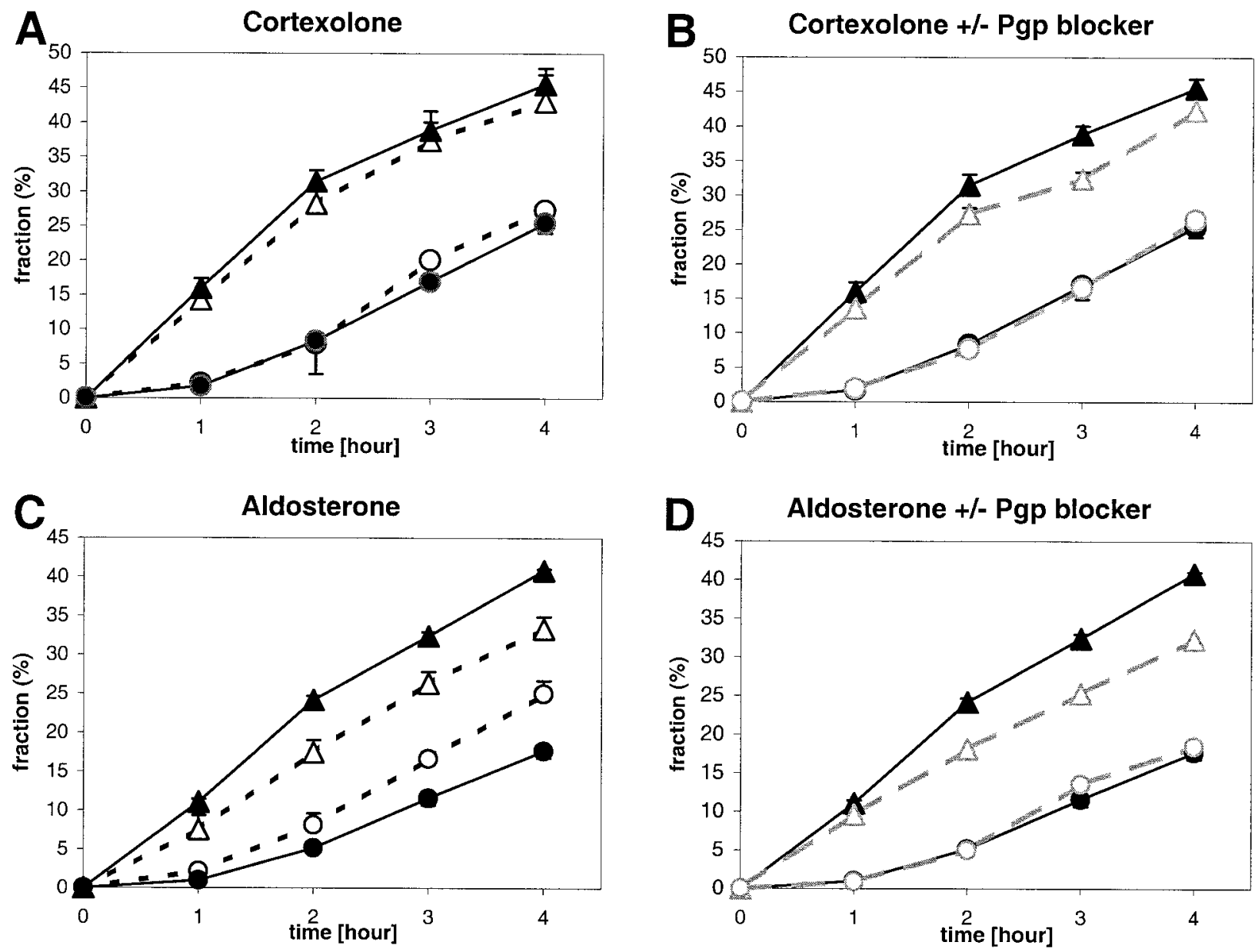

Figure 3 Activity of $\left[{ }^{3} \mathrm{H}\right]$ cortexolone $(\mathrm{A}, \mathrm{B})$ and $\left[{ }^{3} \mathrm{H}\right]$ aldosterone $(\mathrm{C}, \mathrm{D})$ present in medium at different time points after adding $\left[{ }^{3} \mathrm{H}\right]$ steroid to the opposite compartment at $t=0$. (A, C) Transepithelial transport from the basal to apical $(\triangle, \mathbf{\Delta})$ and from the apical to basal $(O, \mathbf{O})$ compartment was measured in wild-type LLC-PK1 (dotted line) or MDR1-transfected LLC-PK1 (solid line) monolayers. (B, D) Transepithelial transport from the basal to apical $(\triangle, \mathbf{\Lambda})$ and from the apical to basal $(\bigcirc, \boldsymbol{0})$ compartment was measured in MDR1-transfected LLC-PK1 monolayers after adding $1 \mu \mathrm{M}$ LY 335979 (broken line) or water (solid line) one hour before the start of the experiment. Results are presented as the fraction of the dose of radioactivity, which is 4 to $5 \mathrm{nM}$ for both steroids, added to the respective compartment. Each point represents the mean of three monolayers \pm S.E.M. In the case of aldosterone the experiment was repeated three times with similar results. Repeated measures ANOVA did not show a significant interaction of time* cell type*transport for either corticosteroid.

the GR in vitro (Kaiser \& Mayer 1980, Schmidt \& Davidson 1987) and in vivo (Acs \& Stark 1975, Duncan \& Duncan 1979, Kaiser \& Mayer 1980). In addition, the high affinity MR ligand aldosterone is only weakly transported by Pgp as demonstrated by our data. These results agree with several in vitro studies on Pgp-mediated transport of aldosterone. Using comparable monolayers to those in this study, Ueda et al. (1992) have demonstrated that aldosterone is moderately transported by the human MDR1 Pgp, while Bourgeois et al. (1993) showed that cortexolone was not and aldosterone was only weakly transported by mdr1b Pgp. The weak transport of aldosterone by Pgp cannot explain why this mineralocorticoid seems to play a limited role in limbic functioning relative to corticosterone, while both steroids bind with similar affinity to MR in vitro (Veldhuis et al. 1982, De Kloet 1991). Moreover, upon administration of tracer amounts of $\left[{ }^{3} \mathrm{H}\right]$ corticosterone and $\left[{ }^{3} \mathrm{H}\right]$ aldosterone to adrenalectomised rodents both steroids are retained very well in limbic brain structures that abundantly express MR (Birmingham et al. 1984). However, in adrenal-intact animals only a small amount of aldosterone is extracted from hippocampal cell nuclei relative to corticosterone, probably because the latter steroid circulates in one hundred to one thousand times higher concentrations in the blood (Yongue \& Roy 1987). Cells conferring aldosterone 
selectivity are present in the periventricular brain areas involved in salt appetite, regulation of the electrolyte balance and autonomic outflow (Seckl 1997, Van Acker et al. 2002). This aldosterone selectivity is due to an $11 \beta$-steroid dehydrogenase that breaks down corticosterone allowing aldosterone access to MR (Seckl 1997). In the hippocampus this reductase activity is absent (Robson et al. 1998). Further studies with mdr1a $(-/-)$ mice are necessary to directly examine the involvement of Pgp in aldosterone uptake in brain.

Although prednisolone is one of the most common clinically used glucocorticoids, this study is the first that shows the fate of prednisolone in brain, whereas other frequently occurring glucocorticoids have been extensively studied before (for review see McEwen et al. 1986). In contrast to uptake into the brain of both corticosterone and aldosterone (McEwen et al. 1968, 1976, De Kloet et al. 1975, De Nicola et al. 1981, Coutard et al. 1987), access of dexamethasone and cortisol to brain is impaired (De Kloet et al. 1974, 1975, Rees et al. 1975, McEwen et al. 1976, Karssen et al. 2001), which has been shown to be caused by the presence of Pgp at the BBB (Meijer et al. 1998, Karssen et al. 2001). We now demonstrate that prednisolone is also hampered in its ability to reach the brain due to the presence of Pgp at this barrier. The active exclusion from the brain provides an explanation for the long-established puzzling phenomenon that GR in the brain is not labelled after in vivo administration of tracer doses of synthetic GR ligands.

In mdr1a null mice the high affinity GR ligand prednisolone is retained by hippocampal and paraventricular neurons as expected based on localisation of GR expressing cells (Van Eekelen et al. 1987). Among the hippocampal subfields, the CA3 pyramidal layer retained the lowest amount of label, in accordance with the neuro-anatomical distribution of hippocampal GR as measured with immunocytochemistry and in situ hybridisation (Van Eekelen et al. 1987, 1988). Pretreatment of mice with 100-fold excess of unlabelled prednisolone abolishes this selective retention in hippocampal cells and the PVN, but does not affect the overall uptake elsewhere in the brain. This indicates that the uniform labelling of the rest of the brain may be due mainly to non-receptor bound, freely moving prednisolone masking specific nuclear retention of low abundantly expressed GR in these areas.

Prednisolone, like dexamethasone, can bind to MR in vitro, but the affinity to this receptor is much lower than to GR to which these steroids bind with very high affinity (<1 nM) (Lan et al. 1981, 1982, De Kloet et al. 1984). In contrast, corticosterone and cortisol bind with high affinity to MR ( $<1 \mathrm{nM})$ and with tenfold lower affinity to GR. In line with this low affinity to the MR, prednisolone has only minor effects on salt retention in the kidney (Karssen \& De Kloet 2000). Using in vivo autoradiography, only very high affinity receptors can be visualised due to the low doses used (De Kloet 1991); e.g. in mdr1a (-/-) mice only $\mathrm{MR}$ can be made visible with $\left[{ }^{3} \mathrm{H}\right]$ cortisol autoradiography as is the case with $\left[{ }^{3} \mathrm{H}\right]$ corticosterone in both wild-type and mutant mice (Karssen et al. 2001). In this study, prednisolone is only able to visualise GR, while the MR has too low an affinity for this steroid for detection.

The lack of effect of pretreatment of unlabelled prednisolone on uptake of $\left[{ }^{3} \mathrm{H}\right]$ prednisolone in wild-type brain indicates that the capacity of Pgp to expel prednisolone from brain is rather high. Furthermore, the monolayer results using $1 \mu \mathrm{M}$ prednisolone also suggest that even at high concentrations Pgp is able to reduce prednisolone concentrations in the brain. Therapeutically, prednisolone is used in high doses in the treatment of diverse medical conditions, including pulmonary, rheumatological, neurological and autoimmune diseases and immune suppression following organ transplantation. Our results suggest that in humans treated with prednisolone, the resultant glucocorticoid levels in brain would be considerably lower than plasma levels. As most peripheral tissues are not protected by a Pgp expressing barrier, peripheral effects would therefore be relatively more potent than central effects, although this does not preclude central effects of prednisolone.

Hippocampal-dependent memory impairment after long-term high dose treatment with prednisone (which is quickly converted to prednisolone in vivo) has been described (Keenan et al. 1996). As hippocampal GR is involved in memory performance (Oitzl \& De Kloet 1992), these effects could be attributed to activation of this receptor. On the other hand, an imbalance in central MR and GR activation as a result of prednisolone treatment could provide an alternative explanation. Differential effects mediated by MR and GR activation on cognitive function have been proposed (De Kloet et al. 1999, Lupien \& Lepage 2001). Although mainly based on animal studies, De Kloet and colleagues (De Kloet 1991, De Kloet et al. 1999) have postulated that a balance between MRand GR-mediated effects critically determines human cognitive functioning. Whether prednisolone reaches the brain or not, due to the prednisolone-induced suppression of pituitary-adrenal activity and thus of adrenocortical secretion, the brain becomes deprived of the endogenous glucocorticoids, corticosterone and cortisol. As a consequence, the ratio of MR/GR occupation will shift towards GR occupation with consequences for cognitive performance, mood and regulation of the behavioural stress response.

As many different drugs used in the clinic are Pgp substrates as well, one has to be aware of undesired side effects when prednisolone (or dexamethasone) is used in conjunction with these drugs. Cotreatment may be able to enhance the brain uptake of the synthetic glucocorticoid. The potent immunosuppressants FK506 and cyclosporine A have been shown to potentiate dexamethasone- 
but not corticosterone-mediated transcriptional activity, apparently due to inhibition of a MDR pump similar to Pgp (Medh et al. 1998). The facilitation of prednisolone's poor penetration into the brain by anti-cancer drugs may also give a rationale to the reported success of combination therapy in treatment of different types of brain tumours (Shibamoto et al. 1999, Wu et al. 1999, Maipang \& Janjindamai 2000). Many anti-cancer drugs (e.g. Vinca alkaloids, anthracyclines, and taxanes) are known to be Pgp substrates. In fact, the first reports of Pgp expression dealt with tumour cells developing multidrug resistance after treatment with a single cytotoxic drug. Further treatment of these tumours is difficult. Provided that the tumour does not disrupt the BBB, brain tumours are even intrinsically resistant to these drugs, as they are behind the BBB (Regina et al. 2001). A combination of drugs including prednisolone, which are all Pgp substrates, may mutually increase their active brain levels by saturating Pgp.

It is remarkable that, in spite of its broad spectrum of substrates (Schinkel et al. 1994), Pgp distinguishes subtle differences in steroid structure. The differences shown in this study reflect the importance of both the 17-hydroxyl and the 11-hydroxyl group in determining the ability of steroids to be transported by Pgp as shown by Bourgeois et al. (1993). Pgp transports steroids having both these hydroxyl groups (such as prednisolone and dexamethasone). Steroids lacking one of these groups (such as aldosterone, corticosterone and cortexolone) and steroids without any of these groups are minimally transported, if at all. The high affinity MR ligand deoxycorticosterone belongs to the latter group and therefore it should easily be retained in the brain. However, although it readily enters the brain (Kraulis et al. 1975), McEwen et al. (1976) have shown that deoxycorticosterone is poorly retained by MR in different brain areas and pituitary of ADX rats. This suggests that there are additional factors, e.g. local metabolism, determining the retention of this mineralocorticoid in potential target areas.

In conclusion, we have demonstrated the involvement of Pgp in hampering the access of the synthetic glucocorticoid prednisolone to mouse brain. The ability of the human MDR1 Pgp to transport prednisolone suggests that prednisolone access to human brain is also impeded. The poor penetration of prednisolone into human brain would presumably lead to a discrepancy in the extent of central and peripheral actions of prednisolone. The subsequent imbalance in MR and GR activation may explain the reported changes in cognitive performance and mood in response to prednisone/prednisolone therapy.

\section{Acknowledgements}

Marc Fluttert, Sergiu Dalm and Dirk-Jan van den Berg are gratefully acknowledged for animal handling and technical assistance. We are grateful to Margret Blom and Heleen Voorwinden for assistance with cell cultures.

\section{References}

Acs Z \& Stark E 1975 Effect of cortexolone on the feedback action of dexamethasone. Experientia 31 1365-1366.

Barnes KM, Dickstein B, Cutler GB, Fojo T \& Bates SE 1996 Steroid transport, accumulation, and antagonism of P-glycoprotein in multidrug-resistant cells. Biochemistry 35 4820-4827.

Belanoff JK, Flores BH, Kalezhan M, Sund B \& Schatzberg AF 2001a Rapid reversal of psychotic depression using mifepristone. Journal of Clinical Psychopharmacology 21 516-521.

Belanoff JK, Gross K, Yager A \& Schatzberg AF $2001 b$ Corticosteroids and cognition. Journal of Psychiatric Research 35 127-145.

Birmingham MK, Sar M \& Stumpf WE 1984 Localization of aldosterone and corticosterone in the central nervous system, assessed by quantitative autoradiography. Neurochemical Research 9 $333-350$

Bourgeois S, Gruol DJ, Newby RF \& Rajah FM 1993 Expression of an $\mathrm{mdr}$ gene is associated with a new form of resistance to dexamethasone-induced apoptosis. Molecular Endocrinology 7 $840-851$.

Cordon-Cardo C, O’Brien JP, Casals D, Rittman GL, Biedler JL, Melamed MR \& Bertino JR 1989 Multidrug-resistance gene (P-glycoprotein) is expressed by endothelial cells at blood-brain barrier sites. PNAS 86 695-698.

Coutard M, Duval D \& Osborne-Pellegrin MJ 1987 In vivo competitive autoradiographic study of $\left[{ }^{3} \mathrm{H}\right]$ corticosterone and $\left[{ }^{3} \mathrm{H}\right]$ aldosterone binding sites within mouse brain hippocampus. Journal of Steroid Biochemistry 28 29-34.

Dantzig AH, Shepard RL, Law KL, Tabas L, Pratt S, Gillespie JS, Binkley SN, Kuhfeld MT, Starling JJ \& Wrighton SA 1999 Selectivity of the multidrug resistance modulator, LY 335979, for P-glycoprotein and effect on cytochrome P-450 activities. Journal of Pharmacology and Experimental Therapeutics 290 854-862.

De Kloet ER 1991 Brain corticosteroid receptor balance and homeostatic control. Frontiers in Neuroendocrinology 12 95-164.

De Kloet ER, Van der Vies J \& De Wied D 1974 The site of the suppressive action of dexamethasone on pituitary-adrenal activity. Endocrinology 94 61-73.

De Kloet ER, Wallach G \& McEwen BS 1975 Differences in corticosterone and dexamethasone binding to rat brain and pituitary. Endocrinology 96 598-609.

De Kloet ER, Veldhuis HD, Wagenaars JL \& Bergink EW 1984 Relative binding affinity of steroids for the corticosterone receptor system in rat hippocampus. Journal of Steroid Biochemistry 21 173-178.

De Kloet ER, Vreugdenhil E, Oitzl MS \& Joëls M 1998 Brain corticosteroid receptor balance in health and disease. Endocrine Reviews 19 269-301.

De Kloet ER, Oitzl MS \& Joëls M 1999 Stress and cognition: are corticosteroids good or bad guys? Trends in Neurosciences $\mathbf{2 2}$ 422-426.

De Nicola AF, Tornello S, Weisenberg L, Fridman O \& Birmingham MK 1981 Uptake and binding of $\left[{ }^{3} \mathrm{H}\right]$ aldosterone by the anterior pituitary and brain regions in adrenalectomized rats. Hormone and Metabolic Research 13 103-106.

Duncan MR \& Duncan GR 1979 An in vivo study of the action of antiglucocorticoids on thymus weight ratio, antibody titre and the adrenal-pituitary-hypothalamus axis. Journal of Steroid Biochemistry 10 245-259.

Gaillard PJ \& De Boer AG 2000 Relationship between permeability status of the blood-brain barrier and in vitro permeability coefficient of a drug. European Journal of Pharmaceutical Sciences 12 95-102. 
Jette L, Pouliot JF, Murphy GF \& Béliveau R 1995 Isoform I (mdr3) is the major form of P-glycoprotein expressed in mouse brain capillaries. Evidence for cross-reactivity of antibody C219 with an unrelated protein. Biochemical Journal 305 761-766.

Kaiser N \& Mayer M 1980 Studies on the antiglucocorticoid action of 11-deoxysteroids in rat thymocytes: discrepancies between in vivo and in vitro effects. Journal of Steroid Biochemistry 13 729-732.

Karssen AM \& De Kloet ER 2000 Synthetic glucocorticoids. In Encyclopedia of Stress, pp 566-570. Ed. G Fink. San Diego, CA, USA: Acadamic Press.

Karssen AM, Meijer OC, Van der Sandt ICJ, Lucassen PJ, De Lange ECM, De Boer AG \& De Kloet ER 2001 Multidrug resistance P-glycoprotein hampers the access of cortisol but not of corticosterone to mouse and human brain. Endocrinology 142 2686-2694.

Keenan PA, Jacobson MW, Soleymani RM, Mayes MD, Stress ME \& Yaldoo DT 1996 The effect on memory of chronic prednisone treatment in patients with systemic disease. Neurology 47 1396-1402.

Kraulis I, Foldes G, Traikov H, Dubrovsky B \& Birmingham MK 1975 Distribution, metabolism and biological activity of deoxycorticosterone in the central nervous system. Brain Research $\mathbf{8 8}$ $1-14$.

Lan NC, Matulich DT, Morris JA \& Baxter JD 1981 Mineralocorticoid receptor-like aldosterone-binding protein in cell culture. Endocrinology 109 1963-1970.

Lan NC, Graham B, Bartter FC \& Baxter JD 1982 Binding of steroids to mineralocorticoid receptors: implications for in vivo occupancy by glucocorticoids. Journal of Clinical Endocrinology and Metabolism $\mathbf{5 4}$ 332-342.

Lupien SJ \& Lepage M 2001 Stress, memory, and the hippocampus: can't live with it, can't live without it. Behavioural Brain Research 127 137-158.

McEwen BS, Weiss JM \& Schwartz LS 1968 Selective retention of corticosterone by limbic structures in rat brain. Nature $\mathbf{2 2 0}$ 911-912.

McEwen BS, De Kloet ER \& Wallach G 1976 Interactions in vivo and in vitro of corticoids and progesterone with cell nuclei and soluble macromolecules from rat brain regions and pituitary. Brain Research 105 129-136.

McEwen BS, De Kloet ER \& Rostene W 1986 Adrenal steroid receptors and actions in the nervous system. Physiological Reviews 66 $1121-1188$

Maipang MV \& Janjindamai SH 2000 Successful combination chemotherapy (vincristine, procarbazine, etoposide, and prednisolone) in the treatment of inoperable, radioresistant low grade astrocytoma: a case report. Journal of the Medical Association of Thailand 83 1525-1529.

Medh RD, Lay RH \& Schmidt TJ 1998 Agonist-specific modulation of glucocorticoid receptor-mediated transcription by immunosuppressants. Molecular and Cellular Endocrinology 138 $11-23$.

Meijer OC, De Lange ECM, Breimer DD, De Boer AG, Workel JO \& De Kloet ER 1998 Penetration of dexamethasone into brain glucocorticoid targets is enhanced in mdr1a P-glycoprotein knockout mice. Endocrinology 139 1789-1793.

Oitzl MS \& De Kloet ER 1992 Selective corticosteroid antagonists modulate specific aspects of spatial orientation learning. Behavioral Neuroscience 106 62-71.

Pariante CM, Makoff A, Lovestone S, Feroli S, Heyden A, Miller AH \& Kerwin RW 2001 Antidepressants enhance glucocorticoid receptor function in vitro by modulating the membrane steroid transporters. British Journal of Pharmacology 134 1335-1343.

Rees HD, Stumpf WE \& Sar M 1975 Autoradiographic studies with $\left[{ }^{3} \mathrm{H}\right]$ dexamethasone in the rat brain and pituitary. In Anatomical Neuroendocrinology, pp 262-269. Eds WE Stumpf \& L Grant. Basel: S Karger.
Regina A, Demeule M, Laplante A, Jodoin J, Dagenais C, Berthelet F, Moghrabi A \& Beliveau R 2001 Multidrug resistance in brain tumors: roles of the blood-brain barrier. Cancer and Metastasis Reviews 20 13-25.

Robson AC, Leckie CM, Seckl JR \& Holmes MC 1998 11[beta]Hydroxysteroid dehydrogenase type 2 in the postnatal and adult rat brain. Molecular Brain Research 61 1-10.

Schinkel AH 1999 P-glycoprotein, a gatekeeper in the blood-brain barrier. Advanced Drug Delivery Reviews 36 179-194.

Schinkel AH, Smit JJ, Van Tellingen O, Beijnen JH, Wagenaar E, Van Deemter L, Mol CAAM, Van der Valk MA, Robanus Maandag EC, Te Riele HP, Berns AJM \& Borst P 1994 Disruption of the mouse mdr1a P-glycoprotein gene leads to a deficiency in the blood-brain barrier and to increased sensitivity to drugs. Cell $\mathbf{7 7}$ 491-502.

Schinkel AH, Wagenaar E, Van Deemter L, Mol CAAM \& Borst P 1995 Absence of the mdr1a P-glycoprotein in mice affects tissue distribution and pharmacokinetics of dexamethasone, digoxin, and cyclosporin A. Journal of Clinical Investigation 96 1698-1705.

Schmidt TJ \& Davidson CJ 1987 The antiglucocorticoid, cortexolone, fails to promote in vitro activation of cytoplasmic glucocorticoid receptors from the human leukemic cell line CEM-C7. Journal of Steroid Biochemistry 26 329-336.

Seckl JR 1997 11ß-Hydroxysteroid dehydrogenase in the brain: a novel regulator of glucocorticoid action? Frontiers in Neuroendocrinology 18 49-99.

Shibamoto Y, Sasai K, Oya N \& Hiraoka M 1999 Systemic chemotherapy with vincristine, cyclophosphamide, doxorubicin and prednisolone following radiotherapy for primary central nervous system lymphoma: a phase II study. Journal of Neuro-Oncology 42 161-167.

Starling JJ, Shepard RL, Cao J, Law KL, Norman BH, Kroin JS, Ehlhardt WJ, Baughman TM, Winter MA, Bell MG, Shih C, Gruber J, Elmquist WF \& Dantzig AH 1997 Pharmacological characterization of LY 335979: a potent cyclopropyldibenzosuberane modulator of P-glycoprotein. Advances in Enzyme Regulation 37 335347.

Thiebaut F, Tsuruo T, Hamada H, Gottesman MM, Pastan I \& Willingham MC 1989 Immunohistochemical localization in normal tissues of different epitopes in the multidrug transport protein P170: evidence for localization in brain capillaries and crossreactivity of one antibody with a muscle protein. Journal of Histochemistry and Cytochemistry 37 159-164.

Ueda K, Okamura N, Hirai M, Tanigawara Y, Saeki T, Kioka N, Komano T \& Hori R 1992 Human P-glycoprotein transports cortisol, aldosterone, and dexamethasone, but not progesterone. Journal of Biological Chemistry $26724248-24252$.

Ueda K, Kino K, Taguchi Y, Yamada K, Saeki T, Tanigawara Y \& Komano T 1996 Role of P-glycoprotein in the transport of hormones and peptides. In Multidrug Resistance in Cancer Cells: Molecular, Biochemical, Physiological, and Biological Aspects, pp 303-319. Eds S Gupta \& T Tsuruo. Chichester, UK: John Wiley.

Van Acker SABE, Oitzl MS, Fluttert MF \& De Kloet ER 2002 Centrally regulated blood pressure response to vasoactive peptides is modulated by corticosterone. Journal of Neuroendocrinology 14 56-63.

Van de Vrie W, Marquet RL, Stoter G, De Bruijn EA \& Eggermont AM 1998 In vivo model systems in P-glycoprotein-mediated multidrug resistance. Critical Reviews in Clinical Laboratory Sciences $\mathbf{3 5}$ $1-57$.

Van Eekelen JAM, Kiss JZ, Westphal HM \& De Kloet ER 1987 Immunocytochemical study on the intracellular localization of the type 2 glucocorticoid receptor in the rat brain. Brain Research 436 $120-128$

Van Eekelen JAM, Jiang W, De Kloet ER \& Bohn MC 1988 Distribution of the mineralocorticoid and the glucocorticoid receptor mRNAs in the rat hippocampus. Journal of Neuroscience Research 21 88-94. 
Veldhuis HD, Van Koppen C, Van Ittersum M \& De Kloet ER 1982 Specificity of the adrenal steroid receptor system in rat hippocampus. Endocrinology 110 2044-2051.

Wu HG, Kim IH, Ha SW, Park CI, Bang YJ \& Huh DS 1999 Survival improvement with combined radio-chemotherapy in the primary central nervous system lymphomas. Journal of Korean Medical Science 14 565-570.

Yamazaki M, Neway WE, Ohe T, Chen I, Rowe JF, Hochman JH, Chiba M \& Lin JH 2001 In vitro substrate identification studies for P-glycoprotein-mediated transport: species difference and predictability of in vivo results. Journal of Pharmacology and Experimental Therapeutics 296 723-735.

Yongue BG \& Roy EJ 1987 Endogenous aldosterone and corticosterone in brain cell nuclei of adrenal-intact rats: regional distribution and effects of physiological variations in serum steroids. Brain Research 436 49-61.

Received 31 May 2002

Accepted 14 June 2002 